\title{
ESTRATÉGIAS PARA EDUCAÇÃO AMBIENTAL SOBRE O ECOSSISTEMA MANGUEZAL NA EDUCAÇÃO BÁSICA
}

\author{
Rita Albuquerque ${ }^{1}$ \\ Marcos Santos ${ }^{2}$ \\ Rafaela Maia ${ }^{3}$
}

\begin{abstract}
Resumo: Os manguezais possuem diversas funções naturais de importância ecológica e socioeconômica. O ambiente escolar é ideal para ampliar a consciência e atitudes adequadas para sua utilização. Foi implementada estratégias metodológicas para Educação Ambiental, por meio da produção de materiais didático-pedagógicos, sobre o ecossistema manguezal em diferentes etapas da educação básica. Os professores apresentaram conhecimento parcialmente satisfatório e insatisfatório sobre o assunto. Já os alunos após a intervenção didática apresentaram resultados satisfatórios. Os resultados insatisfatórios dos professores e dos alunos são reflexos da ausência de materiais didáticos específicos e de cursos de formação continuada para professores.
\end{abstract}

Palavras-chave: Intervenções Ambientais; Ambiente Escolar; Impactos.

Abstract: Mangroves have several natural functions of ecological and socioeconomic importance. The school environment is ideal for increasing awareness and appropriate attitudes for its use. Methodological strategies for environmental education were implemented, through the production of didacticpedagogical materials, about the mangrove ecosystem in different stages of basic education. The teachers presented partially satisfactory and unsatisfactory knowledge on the subject. Students after the didactic intervention showed satisfactory results. The unsatisfactory results of teachers and students reflect the absence of specific didactic materials and of continuing education courses for teachers.

Keywords: Environmental Interventions; School Environment; Impacts.

\footnotetext{
1 Instituto Federal do Ceará. E-mail:ritavasconceloslouzada@gmail.com, Link para o Lattes: http://lattes.cnpq.br/7803738326459278

2 Instituto Federal do Ceará .E-mail:marcosrob20@gmail.com, Link para o Lattes: http://lattes.cnpq.br/8841778978127641

${ }^{3}$ Instituto Federal do Ceará. E-mail:rafaelamaia@ifce.edu.br, Link para o Lattes: http://lattes.cnpq.br/9316001630165818
} 


\section{Introdução}

O manguezal é um ecossistema costeiro que ocupa regiões tropicais em todo o mundo (MAIA et al., 2019, p. 3). Desempenha diversas funções naturais de importância ecológica, dentre as quais se destacam o fato de funcionarem como berçários naturais para o desenvolvimento de inúmeras espécies da fauna e flora, proteção das zonas costeiras, margens de estuários, rios, hidrovias e zonas urbanas contra a erosão, além de serem propícios para prática do turismo ecológico e Educação Ambiental (MEDEIROS; CARVALHO; PIMENTA, 2014, p.68).

No entanto, o fator que mais tem contribuído para o destaque do manguezal como ecossistema é o fato de ser considerado vital para a manutenção dos estoques pesqueiros (MAIA et al., 2019, p. 5). Além disso, esse ecossistema produz bens e serviços para a sociedade, representando a principal fonte de renda e subsistência para inúmeras comunidades tradicionais, destacando-se o extrativismo de macroinvertebrados bentônicos, como os moluscos bivalves e crustáceos (SOUTO; MARTINS, 2009, p. 2).

A intensa utilização de recursos naturais, principalmente pela intensa expansão urbana, carcinicultura, serviços industriais, dentre outras atividades antrópicas, vem ameaçando a existência do ecossistema manguezal nas últimas décadas (MAIA et al., 2019, p. 3). A falta de conscientização, em detrimento da sua importância, leva a rápida exploração desses benefícios naturais por meio de atividades comerciais que trazem lucros imediatos e o crescimento das cidades (CORREIA, 2015, p. 186).

Daí a necessidade de programas e ações para recuperar e conservar o ecossistema manguezal. Dentre eles, podemos destacar a Educação Ambiental, com o objetivo de formar cidadãos, com senso crítico aguçado, no que diz respeito aos processos de destruição do ecossistema (TEIXEIRA, 2019, p. 88). Assim, o ambiente escolar torna-se ideal para ampliar a consciência, princípios, atitudes e qualidades adequadas ao meio (OLIVEIRA et al., 2020, p.12).

Nesse contexto, algumas ações já foram realizadas em escolas a fim de sensibilizar a comunidade escolar sobre os impactos presentes no ecossistema manguezal. Dentre as ações, podemos destacar Farias e Andrade (2010), que realizaram um estudo acerca do manguezal que margeia o Rio Sergipe com alunos do ensino fundamental de escolas públicas e privadas de Aracaju. Rodrigues e Farrapeira (2008), também executaram estudos com alunos de escolas públicas do Ensino Fundamental II e do Ensino Médio de Pernambuco que moravam próximos ao manguezal do Rio Jiquiá, afluente do Rio Tejipió. Silva; Amaral; Oliveira (2012) realizaram uma análise a respeito das distintas concepções de estudantes de uma escola pública do Ensino Fundamental da cidade do Recife que se localiza às margens do manguezal. Todavia, ainda são incipientes os trabalhos realizados com alunos do ensino básico para conservação desse ecossistema. 
Dessa forma, o presente trabalho visa apresentar uma proposta metodológica de trabalho como uma possibilidade de diminuir os impactos ambientais costeiros, causados pela população residente nas áreas próximas a manguezais, partindo do âmbito escolar para a comunidade. Esse estudo intenciona, também, contribuir para a Educação Ambiental já que seus atores são alunos e professores de escolas públicas, os quais moram e estudam em regiões circunvizinhas à região estudada.

\section{Referencial Teórico}

\section{Ecossistema Manguezal}

O ecossistema manguezal está presente em regiões costeiras abrigadas por comunidades ribeirinhas, principalmente áreas estuarinas e lagoas costeiras com comunicação direta com o mar (ALMEIDA et al., 2014, p. 3). No Brasil, os mangues ocupam uma fração significativa do litoral, cerca de $92 \%$ da linha de costa entre o extremo norte no Oiapoque, no Estado do Amapá até seu limite sul na cidade de Laguna, em Santa Catarina (SCHAEFFER-NOVELLI, 2018, p. 25). Mundialmente são conhecidos 28 gêneros e cerca de 70 espécies de mangue, sendo 17 destas exclusivas do ecossistema manguezal (TOMLINSON, 2016, p. 420).

As composições faunísticas presente nos manguezais manifestam uma sequência de adaptações contribuindo para a exploração destes em três dimensões: abrangendo desde o solo como também a copa das árvores, migram com a dinâmica das marés e perfuram substratos (OLIVEIRA; CARDOSO; CRUZ, 2019, p. 15).

A importância desse ecossistema, considerado como um dos ambientes costeiros mais produtivos, atuando como berçário e refúgio de muitas espécies marinhas (OLIVEIRA; CARDOSO; CRUZ, 2019, p. 15). Funcionando ainda como moradia para muitas populações de baixa renda que se instalam nessas áreas para garantir seu sustento por meio dos recursos extraídos do manguezal (BARBOSA; FURRIER, 2013, p. 4).

Os manguezais são reconhecidos pelo Código Florestal (Art. $4^{\circ}$ da Lei 12.652/12) como Área de Preservação Permanente. Todavia, sua utilização ainda acontece de forma descontrolada, o que ocasiona a destruição e degradação do habitat, através, por exemplo, do descarte de resíduos sólidos, aterros e o lançamento de petróleo em locais inadequados do estuário (ALBUQUERQUE et al., 2015, p.4).

\section{Educação Ambiental para o Ecossistema Manguezal}

Vários autores descrevem ações de Educação Ambiental para o ecossistema manguezal, dentre eles, destaca-se o trabalho de Albuquerque; Farias; Maia (2015), cujo objetivo foi conhecer a percepção ambiental dos pescadores em duas áreas pesqueiras no município de Acaraú, Ceará, sobre o manguezal. As coletas dos dados foram feitas por meio de questionários e

revista brasileira educação ambiental 
entrevistas. No entanto, constatou-se que estes apresentaram uma percepção ambiental distinta, ou seja, fazendo-se necessárias ações de Educação Ambiental contínuas com a colaboração entre órgãos competentes e associações de pescadores.

Em conformidade com o trabalho de Silva, Frazão, e D' oliveira (2010), foram abordadas ações realizadas em comunidades próximas ao manguezal no município de Natal-RN. Com a coleta de dados, a partir do diagnóstico dos alunos do $6^{\circ}$ ano do ensino fundamental, sobre seus conhecimentos em relação ao manguezal, por meio da utilização de questionários anteriores e posteriores às ações educativas, tais como, palestras, dinâmicas e a aula passeio do barco escola Chama-Maré. As ações educativas empregadas demonstraram de forma significativa o aumento da compreensão dos alunos sobre a importância do ecossistema manguezal, minimizando os conceitos errôneos que eram estabelecidos pela cultura desses alunos.

\section{O uso de materiais didáticos para a Educação Ambiental}

Jacobi afirma que a Educação Ambiental no ambiente escolar, deve ser efetiva e servir como estímulo, construindo nos discentes um ponto de vista ambiental crítico sobre o que é correto no que diz respeito ao papel do cidadão responsável e à garantia do desenvolvimento sustentável. Diante disso, a transposição didática realizada nesses ambientes, deve ser efetuada como referência das experiências, intenções, interpretações e valores dos professores, interligando o contexto social e a área onde as escolas estão inseridas (JACOBI, 2003).

No ramo da Educação Ambiental, é notória a produção de material didático pedagógico, de caráter audiovisual ou impresso. Apesar disso, ainda é precária a reflexão desses quanto os objetivos mantidos pelo Programa Nacional de Educação Ambiental, tampouco, no que diz respeito à realidade sociocultural local (RODRIGUES; COLESANTII, 2008).

Os jogos didático-pedagógicos são uma modalidade desses materiais, os quais se configuram em três momentos que são eles, problematização inicial, no qual os alunos expõem seus conhecimentos prévios, a organização do conhecimento, onde, estimula a compreensão e problematização do tema proposto, mediado pelo docente, e a aplicação do conhecimento, a qual avalia e interpreta situações anteriores e atuais, adquiridas através do mesmo entendimento (PEDROSO, 2009, p. 2).

Os materiais didáticos contribuem para o ensino de Educação Ambiental com foco no ecossistema manguezal, como destacam os trabalhos de Silveira e Alves (2008), o qual reconhece a utilização da fotografia como ferramenta, que propicia a garantia de trabalhos sobre Educação Ambiental, sendo esta uma modalidade de propriedade artística, que estimula a integração dos indivíduos participantes, através da interação lúdica de forma criativa. 
A utilização de cartilhas, com uma linguagem acessível para os alunos, foi destacada no trabalho de Pinheiro, et al., (2010), como importante ferramenta para o estímulo de boas condutas para discentes que residem em áreas próximas ao ecossistema manguezal. Essa prática esclareceu várias dúvidas dos discentes e da comunidade envolvida e, certamente, foi importante para preservação das gerações futuras para com os manguezais. Ações como estas devem ser realizadas em áreas estuarinas do município de Acaraú, Ceará, pois se encontram com alta vulnerabilidade de impactos antrópicos, causando o desequilíbrio da dinâmica do ecossistema manguezal, o qual se encontra muito impactado devido a sua ocupação pelas populações que residem próximo a esse ecossistema (ARAÚJO et al., 2009, p. 6; MAIA, 2016, p. 19).

\section{Material e Métodos}

O presente estudo caracteriza-se como pesquisa com métodos mistos, de cunho qualitativo e quantitativo. Foi desenvolvido no município de Acaraú, localizado no litoral oeste do estado do Ceará, em duas escolas públicas de ensino básico, uma de nível infantil e outra de nível fundamental, ambas situadas próximo ao manguezal.

A amostragem contou com a participação de 7 professores do ensino infantil, 14 professores do fundamental das séries iniciais ( $5^{\circ}$ ano), e finais ( $7^{\circ}$ ano), das duas instituições. Na instituição de ensino infantil, participaram duas turmas, sendo 15 alunos do infantil " 4 " e 14 alunos do infantil " 5 ", com faixa etária de 4 a 5 anos respectivamente. $\mathrm{Na}$ instituição de ensino fundamental, participaram do estudo duas turmas, sendo 13 alunos do $5^{\circ}$ ano, e 17 alunos do $7^{\circ}$ ano, com faixa etária de 10 e 14 anos respectivamente.

Para obtenção dos dados foram realizados encontros semanais durante dois meses, em torno de uma hora-aula para cada turma. Os instrumentos utilizados foram observações, entrevistas, jogos, cartilhas e questionários. Também se realizou intervenções didáticas com os alunos do ensino infantil e ensino fundamental, como forma de sensibilização da Educação Ambiental, levando em conta o ecossistema manguezal.

Ao todo, o desenvolvimento deste estudo teve quatro etapas, descritas a seguir. Para cada público foi elaborado um tipo de investigação de caráter subjetivo.

\section{Etapas do Estudo}

\section{Diagnóstico docente}

A primeira etapa do estudo foi o diagnóstico através de uma entrevista gravada sobre os conhecimentos prévios a respeito do ecossistema manguezal que envolveu docentes tanto do ensino infantil quanto do ensino fundamental. Cada uma das instituições pesquisadas, contou com essa análise diagnóstica, realizadas com todos os professores das turmas avaliadas, independentemente 
de sua área de formação, acerca do conhecimento e da abordagem de conteúdos sobre o manguezal em suas aulas.

As entrevistas foram compostas de nove (9) perguntas discursivas que abordaram a temática de conhecimentos sobre o ecossistema manguezal. Cada entrevista teve durabilidade de cinco a dez minutos de acordo com a disponibilidade do docente.

\section{Diagnóstico discente - Educação Infantil}

Antes da intervenção didática, foi realizada uma conversa informal com os alunos para verificação dos conhecimentos prévios sobre os manguezais, dando ênfase à fauna e flora desse ecossistema. Após, aconteceu uma intervenção didática onde foram utilizados recursos de animação, onde os alunos puderam enfatizar suas percepções sobre o tema manguezal, no que diz respeito aos impactos causados ao ecossistema.

Para concluir a consciência ecológica sobre esse assunto, os alunos foram divididos em grupos, onde cada um foi contemplado com um jogo de quebra-cabeça, denominado "Educa Mangue" (Figura 1), com a fauna e flora presentes em um mangue não impactado e impactado, tendo como objetivo avaliar a concepção dos discentes sobre preservação e poluição desse ecossistema. O jogo foi confeccionado pelos autores.
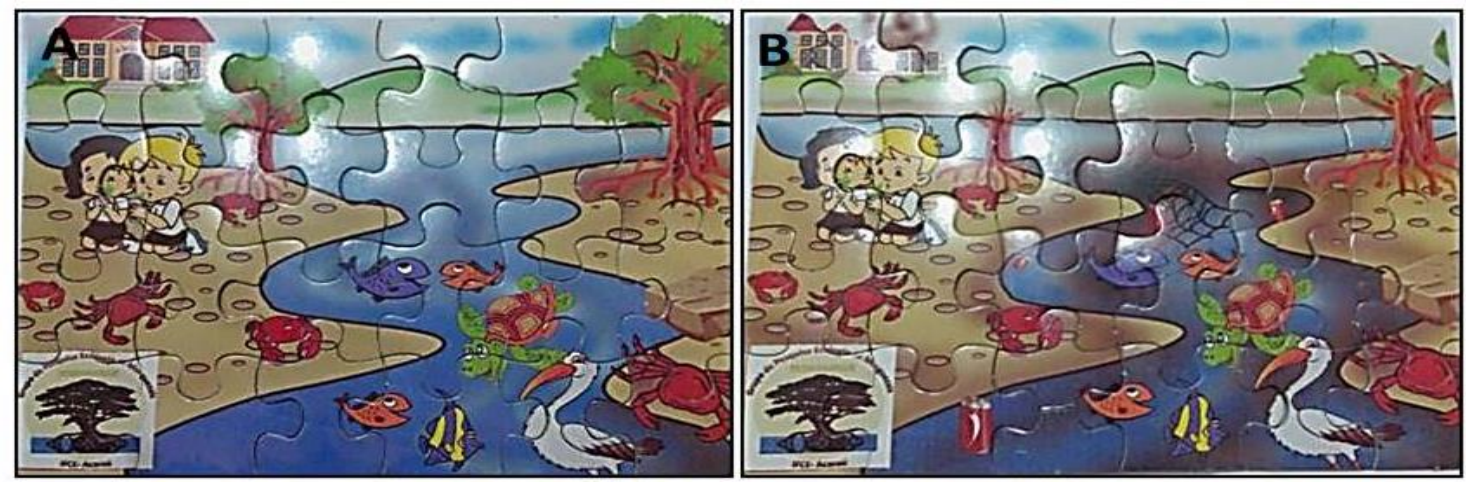

Figura 1: Modelo do quebra-cabeça Educa Mangue aplicado na instituição de ensino infantil: (A) Manguezal com baixo impacto; (B) Manguezal impactado. Fonte: Autores (2016).

Depois da montagem, os discentes expuseram suas considerações, acerca dos ambientes desvendados em cada quebra-cabeça. Todo diagnóstico foi realizado em cerca de meia hora para cada turma.

\section{Diagnóstico discente - Ensino Fundamental}

Antes da intervenção didática, tanto os alunos das séries iniciais ( $5^{\circ}$ ano) quanto os das séries finais ( $7^{\circ}$ ano), responderam um questionário. Na turma do $5^{\circ}$ ano (série inicial), foi aplicado um questionário contendo sete (07) questões, seis (06) delas eram subjetivas e apenas uma era de múltipla escolha. 
Para os alunos das séries finais $\left(7^{\circ}\right.$ ano), foi utilizado como instrumento avaliativo um questionário estruturado, composto por treze (13) questões, sendo duas (02) de múltipla escolha e onze (11) discursivas. Esses diagnósticos foram realizados antes e após uma intervenção didática sobre o ecossistema manguezal.

O questionário teve aproximadamente 20 minutos para ser concluído, e em seguida, ele foi recolhido.

Como uma estratégia para consolidar o assunto abordado, os alunos foram contemplados com uma cartilha intitulada "Educa Mangue" (Figura 2), ela foi produzida pelos próprios autores, considerando os dados obtidos pelo grupo de pesquisa de Ecologia de Manguezais (ECOMANGUE), do Instituto Federal de Educação, Ciência e Tecnologia do Estado do Ceará, campus de AcaraúCeará.

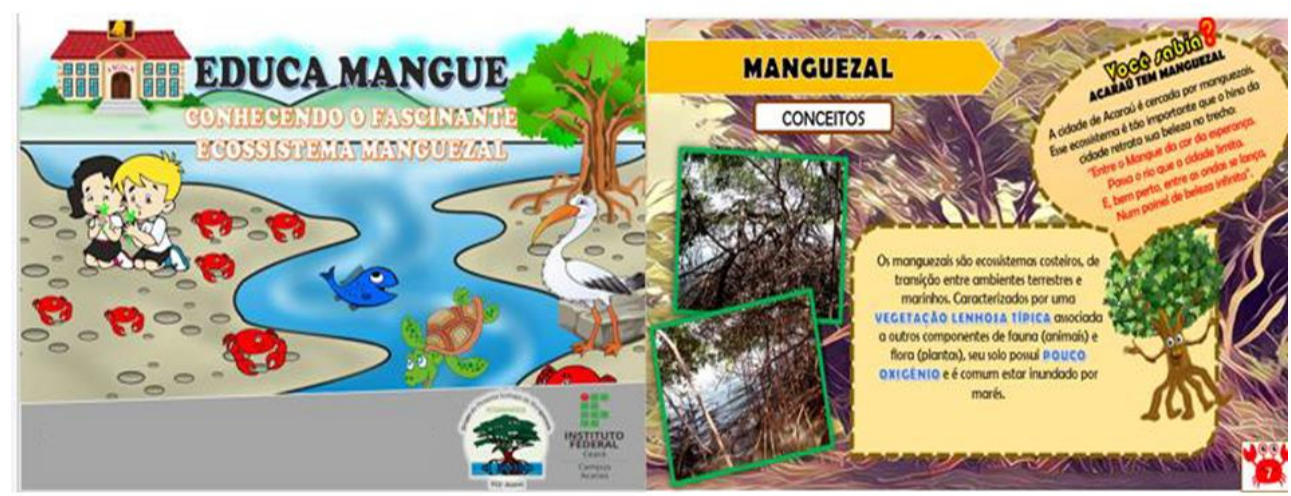

Figura 2: Modelo da cartilha Educa Mangue, como instrumento de avalição para o ensino de Educação Ambiental para o ecossistema manguezal, utilizada na Escola de Ensino Fundamental. Fonte: Autores (2016).

Essa intervenção didática contribuiu para aumentar o conhecimento dos alunos sobre Ecologia e Educação Ambiental do ecossistema manguezal, uma vez que aproximou os conteúdos tanto de ciências naturais como de outras disciplinas, por meio da caracterização da fauna e flora, as quais compõem esse ecossistema, seu papel ecológico, os tipos de mangue existentes na região, impactos ambientais nele presentes, noções de Educação Ambiental e atividades didáticas acerca do conteúdo empregado na cartilha.

\section{Diagnóstico Final}

Essa etapa caracterizou-se pela contabilização dos dados dos questionários e análise da eficácia das intervenções didáticas empregadas para cada nível de ensino. Para quantificar os dados obtidos foi utilizada a metodologia de Pereira; Farrapeira; Pinto (2006), que classifica as respostas em três categorias: "Satisfatórias", para as respostas completas nas quais os alunos demonstraram ter um conhecimento significativo do assunto; "Parcialmente satisfatórias", para aquelas onde os alunos demonstraram ter um conhecimento 
mínimo a razoável (mas incompleto) do assunto abordado; e "Insatisfatórias", no caso dos alunos que demonstraram ou declararam nada saber sobre o assunto, ou ainda, quando os mesmos deixaram as questões em branco. Tais critérios não foram empregados para as respostas com opções apenas para "sim" e "não" ou nas que enumeravam a importância dos manguezais para as pessoas e para o meio ambiente.

\section{Resultados e discussão}

\section{Diagnóstico dos docentes do ensino infantil e fundamental}

Dos docentes entrevistados quando questionados sobre o que era manguezal, $43 \%$ responderam de forma satisfatória, citando até três características dos manguezais, $52 \%$ das respostas foram parcialmente satisfatória sendo mencionados pelos mesmos entre uma e duas características e apenas $5 \%$ insatisfatória, não sabiam do que se tratava. Questionados sobre o conhecimento do estuário do rio Acaraú, $24 \%$ dos docentes relataram que conhecem ou já visitaram o estuário, $19 \%$ relatam que já ouviram falar, porém, nunca visitaram, e $57 \%$ dos docentes responderam que não conhecem.

Quando abordado o assunto de aulas ministradas sobre o manguezal, apenas $19 \%$ abordam o assunto de forma parcialmente satisfatória, enquanto $81 \%$ dos docentes responderam de forma insatisfatória, que não abordam o tema em suas aulas e o quesito satisfatório não foi computado. Quanto ao conhecimento da fauna e a flora do manguezal, apenas $14 \%$ dos docentes responderam de forma satisfatória conhecendo alguns organismos, $67 \%$ foram parcialmente satisfatórias, limitando-se somente as espécies que se alimentam, e 19\% foram insatisfatórias uma vez que não conhecem nada do ecossistema.

Com relação ao material didático utilizado para ministrar as aulas, apenas $24 \%$ apontaram o critério satisfatório e narraram que os materiais utilizados em suas aulas faziam referência ao manguezal, e $76 \%$ dos professores revelaram insatisfação, relatando que o material didático utilizado, não expunha nada sobre - assunto. O critério parcialmente satisfatório não foi citado. Quando questionados sobre a importância de ensinar o tema manguezal para os alunos, $57 \%$ dos professores foram satisfatórios, expondo apenas que é importante debater com os alunos sobre o manguezal, porém, $43 \%$ parcialmente satisfatório, não dando tanta relevância ao assunto, o quesito insatisfatório não foi computado.

Quando indagados sobre ações realizadas na escola para preservação do ecossistema manguezal, $43 \%$ dos professores apresentaram respostas satisfatórias, porém, as ações se limitam apenas na semana do meio ambiente, $57 \%$ dos relatos foram insatisfatórios com relação ao assunto, respondendo que "não" conheciam ações realizadas na escola para a preservação do ecossistema manguezal. O critério parcialmente satisfatório não foi citado. No entanto, apenas $19 \%$ dos docentes já participaram de alguma conferência sobre Educação 
Ambiental, $5 \%$ participaram de forma parcialmente, e $76 \%$ foram insatisfatórios, relatando nunca ter participado de eventos relacionados ao tema.

Os professores entrevistados quando abordados sobre os obstáculos para abordagem da Educação Ambiental sobre o ecossistema manguezal em sala de aula, revelaram que $19 \%$ são satisfatórios que não possuem dificuldade para abordar o tema em suas aulas, porém, 52\% foram parcialmente satisfatórios, alegando falta de material apropriado, e $29 \%$ insatisfatório, respondendo que não fizeram nenhuma explanação a respeito desse assunto em sala de aula.

Baseado na análise das respostas dos professores pode-se dizer que de forma geral, os docentes não apresentam conhecimento satisfatório sobre o ecossistema manguezal. Pelo fato de as respostas parcialmente satisfatórias e insatisfatórias apresentarem maior ocorrência que a soma das características satisfatórias. Resultados semelhantes foram observados no trabalho de Cardoso, Cardoso e Camarotti (2012), no qual os docentes demonstraram não ter conhecimento prévio sobre esse ecossistema. O distanciamento dos professores sobre o assunto faz com que eles não abordem devidamente o tema em sala de aula (FREITAS et al., 2012, p. 5).

\section{Diagnósticos iniciais e finais dos alunos do ensino infantil}

$\mathrm{Na}$ análise realizada com o público infantil antes das intervenções didáticas planejadas, pôde-se perceber que tanto os alunos do ensino infantil " 4 " quanto os alunos do infantil " 5 ", demonstraram ter conhecimento sobre a fauna existente nos manguezais.

Esse fato foi comprovado em relatos dos discentes sobre os principais representantes faunísticos que viviam no manguezal, sendo que, os mais citados foram: siris e caranguejos. Essa predominância de citações pode estar associada ao fato da maioria de seus pais serem pescadores, como foi relatado no decorrer da conversa com eles. Quanto à flora, os discentes não sabiam identificar como eram as árvores, tampouco suas adaptações. Esse resultado se assemelha ao estudo de Pereira; Farrapeira; Pinto (2006), no qual alunos, das séries finais do ensino fundamental, mostraram possuir um conhecimento aguçado sobre a fauna desse ecossistema, uma vez que suas citações faziam referência a crustáceos, como caranguejos e camarões.

Após a intervenção por meio da aplicação da animação e do jogo de quebra-cabeça, denominado "Educa Mangue", os alunos conseguiram expor sua capacidade crítica sobre o assunto abordado em cada uma das ações didáticas. Eles relataram, após a animação que o ecossistema manguezal exposto na mesma precisava de cuidados, pois a ação antrópica influenciava na destruição do mesmo. Quanto ao jogo de quebra-cabeça, após a montagem os alunos conseguiram manifestar seus conhecimentos de um mangue preservado e impactado e as possíveis causas desse impacto para o ecossistema manguezal e para as pessoas. Após as intervenções, foi perceptível que os alunos

revista brasileira educação ambiental 
conseguiram expressar exemplos de outros animais antes não citados por eles, como por exemplo: tartaruga, garça, dentre outros.

Em um trabalho semelhante, com alunos das séries finais do ensino fundamental, Pereira, Farrapeira e Pinto (2006), os alunos demonstraram que a confecção de um jogo educativo intitulado: "dominó ecológico do manguezal", como apoio para abordagem do tema manguezal, possibilitou a transmissão do conhecimento sobre esse ambiente, uma vez que os discentes fixaram as informações gerais sobre o ecossistema e seus constituintes biológicos, havendo ainda, uma criticidade ao tentar relacionar os elementos expostos ao longo do jogo.

\section{Diagnósticos iniciais e finais dos alunos do ensino fundamental ( $5^{\circ}$ ano).}

Os resultados do diagnóstico inicial das análises dos questionários sobre a percepção dos alunos quanto ao ecossistema manguezal revelaram, através dos indicadores de avaliação, que a comunidade estudantil pesquisada deteve um conhecimento prévio sobre o assunto abordado variando de parcialmente satisfatório a insatisfatório. Os resultados assemelham-se com os estudos de Farrapeira, Silva e Lima (2007), realizado nas comunidades estudantis do Recife, onde também notaram que os alunos detinham um conhecimento relativo sobre o manguezal, possivelmente por viver nas proximidades dele.

As informações a seguir, foram obtidas com a realização de comparação dos dados do questionário inicial (antes da ação educativa) e final (após a ação educativa).

Em resposta a questão: "Escolha dentre as imagens abaixo, (marcando um X) na que representa um manguezal", dos 22 alunos analisados, 86\% escolheram a imagem que representava o manguezal, sendo essa resposta considerada satisfatória, e 14\% escolheram outro ecossistema, portanto, resposta insatisfatória, o critério parcialmente satisfatório não foi registrado. Posteriormente a intervenção, com uma amostra de 13 alunos, observou-se que $92 \%$ dos discentes sabiam distinguir dentre as imagens, qual representava 0 ecossistema manguezal, logo $8 \%$ foi insatisfatório, pois ainda tinham dúvidas em identificar o manguezal.

Em relação à questão: "Desenhe quais plantas você acha que existem no manguezal”, 77\% não souberam desenhar as plantas típicas de manguezais, sendo essas respostas classificadas como insatisfatórias, e apenas $23 \%$ foram consideradas satisfatórias, sendo que desenharam as plantas existentes nos manguezais. O quesito parcialmente satisfatório não foi computado. Após a ação educativa, houve uma inversão nos resultados, pois $77 \%$ dos alunos expressaram satisfatoriamente, em forma de desenho, as plantas existentes nos manguezais, e apenas $23 \%$ foram insatisfatórios, desenhando plantas que não eram predominantes desse ambiente (Figura 3). 


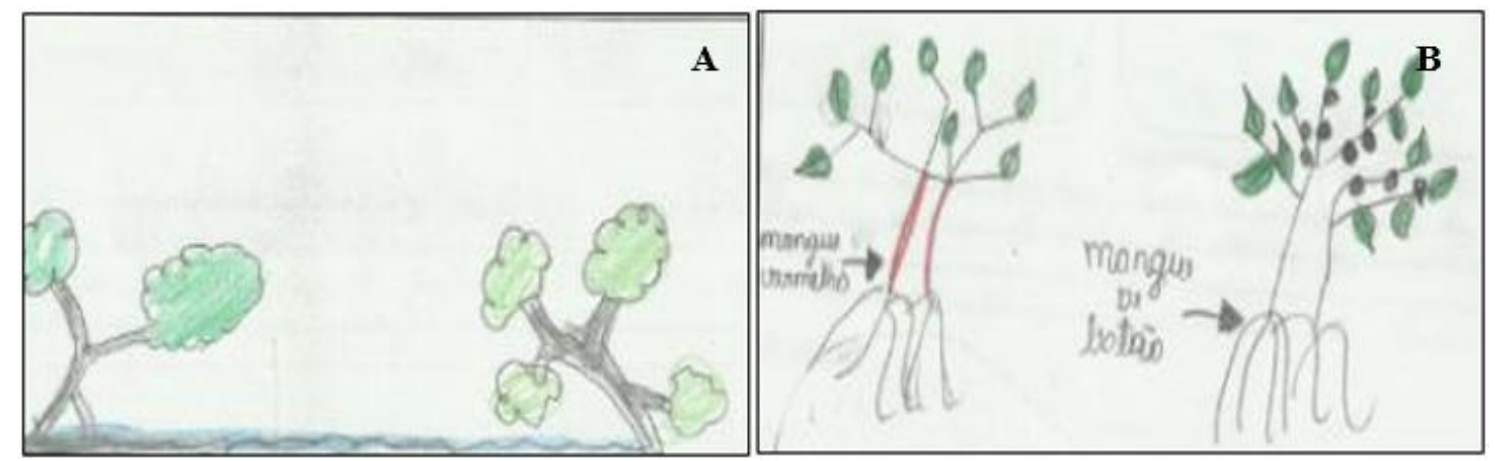

Figura 3: Desenhos dos alunos do $5^{\circ}$ ano. (A) desenho antes da ação didática (insatisfatório);

(B) desenho após a ação didática (satisfatório). Fonte: autores (2016).

Na questão: "Pinte os animais que você acha que existem no manguezal" (Figura 4), os resultados alcançados, revelam que $64 \%$ dos discentes foram parcialmente satisfatórios, onde pintaram até um ou dois animais correspondentes ao ecossistema manguezal, porém 36\% conseguiram diagnosticar de forma satisfatória, pintando de três ou mais desses organismos da fauna. O critério insatisfatório não foi registrado. Posteriormente, com a mediação realizada com o emprego de uma cartilha didática, os discentes atingiram um percentual de $100 \%$ satisfatória em suas respostas, ou seja, todos pintaram corretamente de três a quatro animais que vivem nos manguezais.
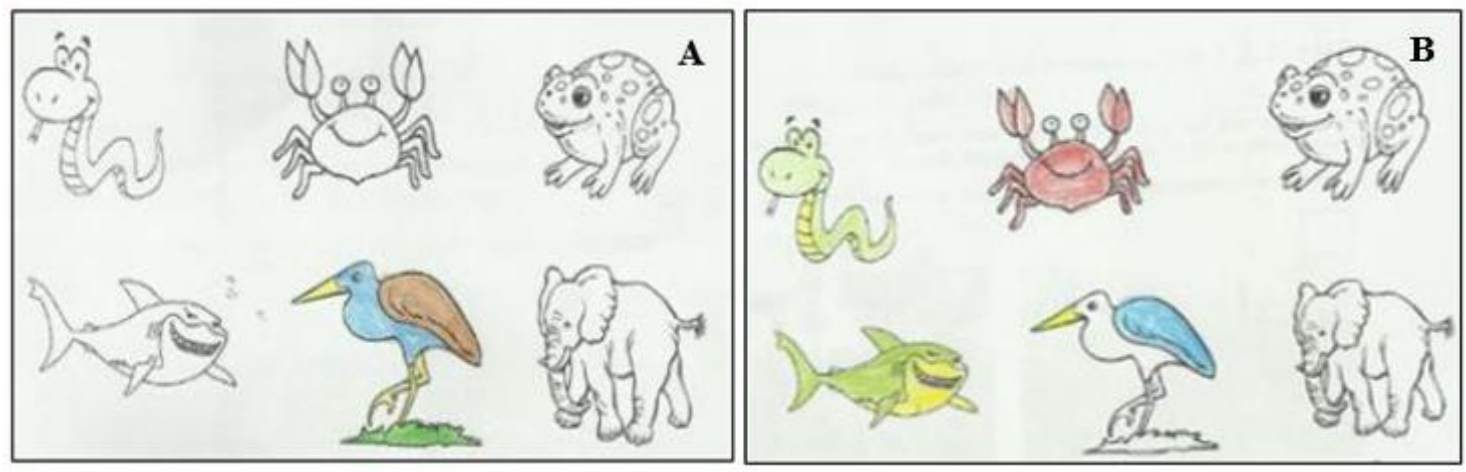

Figura 4: Animais pintados pelos dos alunos do $5^{\circ}$ ano. (A) desenho antes da ação didática (insatisfatório); (B) desenho após a ação didática (satisfatório). Fonte: Autores (2016).

Em relação à questão: "Você sabia que Acaraú tem um manguezal?" O seu professor (a) já tinha lhe dito isso antes?". A alternativa mais citada foi o item que correspondia a reposta "sim" com $59 \%$, e $41 \%$ dos alunos citaram que não sabiam que Acaraú tinha manguezal. Após o intermédio didático, ouve um aumento do percentual satisfatório que passou a ser $85 \%$ uma vez que, assinalaram o item "sim", e apenas 15\% marcaram a opção "não" revelando desconhecimento do manguezal de Acaraú.

Os resultados obtidos na questão "Você já visitou o manguezal?" $50 \%$ dos alunos citaram nunca ter visitado o manguezal, $32 \%$ relataram, ter visitado com os pais, e $14 \%$ disseram já ter visitado com os amigos e $4 \%$ não responderam a esta pergunta. Após a ação didática, tanto a opção "sim, com meus pais" e "não, 
nunca fui", tiveram um percentual de $46 \%$, ou seja, haviam ou não visitado um manguezal, e $8 \%$ mencionaram já ter visitado algum manguezal com os amigos.

Acerca da questão: "Desenhe o que é para você um manguezal destruído e outro preservado", $50 \%$ dos alunos responderam de forma insatisfatória, não colocando em seus desenhos nenhuma característica de um manguezal destruído e preservado, $36 \%$ considerados satisfatórios desenharam características de um manguezal preservado e de um manguezal destruído, e $14 \%$ foram parcialmente satisfatórias, citando apenas uma dessas características. Após o intermédio didático, houve uma variação significativa dos resultados, onde $54 \%$ dos alunos responderam de forma satisfatória por meio de desenhos, retratando um manguezal destruído e um preservado, obteve-se também o percentual de $23 \%$ de respostas parcialmente satisfatórias e insatisfatórias.

Na questão: "Para você o manguezal é importante? Por quê?" $50 \%$ dos alunos responderam de forma parcialmente satisfatória, citando pelo menos uma característica sobre a importância do manguezal, $45 \%$ responderam de forma insatisfatória, fugindo do tema proposto, e $4 \%$ dos alunos responderam de forma satisfatória, destacando até duas características sobre a importância do manguezal. Após a intervenção didática, $46 \%$ das respostas foram satisfatórias, e os mesmos conseguiram relatar que os manguezais funcionavam como áreas de abrigo para espécies da fauna, famílias tiravam seu sustento dessas áreas, porém $31 \%$ foram parcialmente satisfatórias, na qual descreveram apenas uma das inúmeras importâncias dos manguezais e $23 \%$ responderam insatisfatoriamente essa questão.

A análise dos questionários sobre a concepção dos alunos quanto ao ecossistema manguezal após as ações didáticas empregadas para interpretação das respostas, indicaram que os critérios satisfatórios e parcialmente satisfatórios se sobre saíram com relação ao critério insatisfatório, revelando que as ações didáticas foram bem-sucedidas e absorvidas pelos discentes.

Após a intervenção didática, eles demonstraram em forma de desenhos e pinturas que reconheciam os itens contidos nas alternativas e também os enunciados expostos nas questões subjetivas acerca do assunto. Resultados semelhantes foram observados por Garrido e Meirelles (2014), que utilizaram esse método como instrumentos para a coleta de dados empregados nos estudos para avaliar a percepção dos alunos de uma turma de $1^{\circ}$ ano e uma do $5^{\circ}$ ano do ensino fundamental sobre o meio ambiente.

Ainda sobre esse público, foi evidente que os resultados obtidos, após a intervenção didática, com o auxílio da cartilha intitulada "Educa Mangue", tiveram um percentual satisfatório. Esse fato corrobora com o trabalho de Pereira; Farrapeira; Pinto (2006), no qual após a aplicação de uma revista em quadrinhos intitulada "Limpando o manguezal", a qual versava sobre a poluição por meio de resíduos sólidos e a necessidade de ações de conservação ambiental nesse ambiente acrescentando assim novos conhecimentos para os discentes, 
indicando assim percentuais satisfatórios e parcialmente satisfatórios nas respostas dos discentes avaliados.

\section{Diagnósticos iniciais e finais dos alunos do ensino fundamental ( $7^{\circ}$ ano).}

Os resultados do diagnóstico inicial das análises dos questionários sobre a percepção dos alunos quanto ao ecossistema manguezal, revelou que os alunos detêm um conhecimento prévio relativo parcialmente satisfatório e insatisfatório. Os resultados dos conhecimentos prévios dos alunos se assemelham aos resultados obtidos no trabalho de Rodrigues e Farrapeira (2008), revelando que a comunidade estudantil pesquisada detinha um conhecimento prévio que vai de parcialmente satisfatório a insatisfatório sobre o tema manguezal.

Os critérios empregados nas respostas dos discentes sobre suas percepções no que diz respeito ao tema manguezal, mostraram que eles tiveram dificuldades em expor seus conhecimentos sobre 0 assunto. Esse fato foi comprovado através da resolução de algumas questões, nas quais, foi notório o não reconhecimento dos itens contidos nas alternativas assim como os enunciados expostos nas questões subjetivas sobre o assunto. As informações a seguir foram obtidas com a realização de comparação dos dados do questionário inicial (antes da ação educativa) e final (após a ação educativa).

Em resposta aos resultados referente à questão "Para você o que é manguezal?" $53 \%$ dos alunos foram insatisfatórios, não sabiam definir manguezal, $41 \%$ responderam de forma parcialmente satisfatória, conceituaram apenas uma característica de manguezal, e 14\% dos alunos responderam satisfatoriamente, citando duas características sobre o ecossistema manguezal. Após ação didática, o critério parcialmente satisfatório passou a ser de $64 \%$, bem como as respostas satisfatórias que aumentaram para $18 \%$, e as respostas insatisfatórias tiveram um declínio, diminuindo para $18 \%$.

Quando perguntados sobre a diferença entre mangue e manguezal. O percentual insatisfatório foi $88 \%$ dos discentes, não conheciam a diferença entre mangue e manguezal, e $6 \%$ foram satisfatórios e parcialmente satisfatórios onde os alunos relatavam a diferença entre os dois termos. Após a ação educativa, $53 \%$ conseguiram expor de forma satisfatória a diferença entre mangue e manguezal, seguindo das respostas insatisfatórias com 35\% e 12\% parcialmente satisfatória.

Os dados referentes ao questionamento sobre as diferenças entre as plantas do manguezal e outras plantas, $71 \%$ dos discentes responderam de forma insatisfatória uma vez que não sabiam diferenciar, o critério parcialmente satisfatório apresentou um percentual de $23 \%$, na qual citavam apenas uma característica e $6 \%$ dos alunos foram satisfatórios, expondo duas características que as diferem das plantas comuns. Após a intervenção didática, os critérios avaliados sofreram uma moderada alteração, pois os dados satisfatórios passaram a ser $29 \%$, parcialmente satisfatório $18 \%$, e insatisfatório $53 \%$. 
Quanto à questão sobre os animais que vivem nos manguezais, o critério satisfatório foi $47 \%$ já que os discentes mencionaram três ou mais dos animais existentes nos manguezais, enquanto o critério insatisfatório apresentou um percentual de $29 \%$. Os alunos não citaram nenhum animal a respeito do assunto, e $24 \%$, parcialmente satisfatória descrevendo um ou dois desses animais. Observa-se que após a intervenção didática, houve um acréscimo significativo para os critérios avaliados, satisfatórias $70 \%$ parcialmente satisfatórias não houve variações, $24 \%$, já nas respostas insatisfatórias, ocorreu um declínio para $6 \%$.

Em relação à pergunta sobre a importância do manguezal, o critério insatisfatório obteve $53 \%$ das considerações relatadas pelos discentes, já o critério parcialmente satisfatório apresentou 47\%, o critério satisfatório não apresentou resposta. No entanto, após a intervenção didática, o critério satisfatório teve um aumento significativo de $18 \%$, sendo que antes não havia sido registrado. Logo os critérios parcialmente satisfatórios e insatisfatórios, tiveram um declínio, respectivamente de $41 \%$.

$\mathrm{Na}$ questão que versava sobre "Quais dos termos abaixo têm a ver com o manguezal", o item lama $(\mathrm{N}=13)$, peixes, aves, marés $(\mathrm{N}=11)$, insetos, matas abertas e raízes escoras $(\mathrm{N}=10)$, foram os mais mencionados pelos alunos, enquanto o item moluscos de mata arbustiva $(\mathrm{N}=7)$, crustáceo $(\mathrm{N}=6)$, poluição $(\mathrm{N}=4)$ e lixo $(\mathrm{N}=3)$, foram menos destacados. Após a intervenção, os mais representativos foram seis itens, tais como: lama $(\mathrm{N}=16)$ marés, peixe $(\mathrm{N}=15)$, aves $(\mathrm{N}=14)$, raízes, escoras $(\mathrm{N}=13)$, moluscos $(\mathrm{N}=12)$, os menos representados foram, crustáceo e matas arbustivas $(\mathrm{N}=7)$, matas abertas $(\mathrm{N}=4)$, lixo e poluição $(\mathrm{N}=5)$ e insetos $(\mathrm{N}=2)$.

$\mathrm{Na}$ questão que tratava da disciplina que estudaram sobre os manguezais, foram obtidos $59 \%$ para o critério insatisfatório, uma vez que os alunos não haviam estudado sobre o manguezal, $23 \%$ responderam de forma satisfatória, já que os discentes revelaram ter estudado sobre o assunto e $18 \%$ parcialmente satisfatório. Pôde-se perceber que, após a intervenção didática, houve um aumento do critério insatisfatório passando a ser $65 \%$, o quesito satisfatório variou para $29 \%$, e o parcialmente satisfatórias houve um declínio, para $6 \%$.

$\mathrm{Na}$ questão acerca de visitas realizadas ao manguezal, 65\%, já haviam visitado o manguezal e $35 \%$ nunca visitaram. Após a ação didática, a porcentagem de quem havia visitado aumentou para $82 \%$, enquanto o item "não", sofreu um declínio para $18 \%$. Na questão seguinte questionava com o que foi realizada a visita no manguezal, os resultados obtidos foram $(\mathrm{N}=6)$ amigos, $(\mathrm{N}=4)$ pais, $(\mathrm{N}=1)$ escola, outros $(\mathrm{N}=2)$, e apenas $(\mathrm{N}=4)$ não visitaram ou não responderam essa questão. Após a ação didática, o item "pais" foi o mais citado pelos alunos ( $N=9)$, seguido do item "outros" $(\mathrm{N}=4)$ e o item "amigos" em $(\mathrm{N}=3)$ respostas, apenas um aluno não respondeu essa questão.

Em relação à questão: "Conhece alguém que tira seu sustento do manguezal? O que ele (a) Ihe conta a respeito da produção do manguezal?" $59 \%$ dos alunos relataram de forma insatisfatória expressando "não" conhecer 
ninguém. O critério parcialmente satisfatório $23 \%$, citaram apenas que conheciam alguém, mas não sabiam o que essas pessoas retiravam de lá, e $18 \%$ responderam satisfatoriamente essa questão, citando que conheciam essas pessoas e quais produtos elas retiravam dos manguezais. Após a ação didática, pôde-se observar que no percentual do critério insatisfatório um acréscimo relevante, 94\%, logo o percentual satisfatório teve um declínio, passou para $6 \%$ e as respostas parcialmente satisfatórias não foram computadas nesta questão.

Na questão: "Por que, atualmente, os manguezais vêm sofrendo uma grande devastação?" 65\% dos alunos expuseram de forma parcialmente satisfatórias, apenas um fator que prejudicava o manguezal, $29 \%$ de respostas insatisfatórias, onde eles nada responderam sobre o assunto, e apenas uma equivalência de $6 \%$ satisfatórias, nas quais os alunos citaram fatores de degradação do manguezal. Foi observado que, após a intervenção didática, houve um declínio no percentual das repostas parcialmente satisfatórias de 53\%. O mesmo aconteceu nas respostas insatisfatórias passando para 18\%. Já o critério satisfatório teve um aumento de $29 \%$.

Os resultados obtidos na questão: "Em sua opinião, visitas ao ecossistema manguezal e a elaboração de atividades práticas ajudariam você na aprendizagem do assunto?" $53 \%$ responderam de forma insatisfatória, dizendo não ter um senso crítico ou não saber informar, $41 \%$ das respostas foram parcialmente satisfatórias onde eles citaram apenas uma das opções. "Esse tipo de atividade ajuda na compreensão do conteúdo teórico". E apenas $6 \%$ das respostas foram satisfatórias, onde os alunos mencionaram até duas justificativas condizentes, de caráter positivo para sua aprendizagem. Após a intervenção didática, o critério parcialmente satisfatório, declinou para $47 \%$, já no quesito insatisfatório, o percentual permaneceu o mesmo $41 \%$, e o critério satisfatório teve um aumento de $12 \%$.

Em relação à questão: "O que você tem mais curiosidade em saber sobre o manguezal?" $88 \%$ responderam de forma satisfatória, citando e mencionando algumas de suas curiosidades sobre o manguezal. Foram contabilizados $12 \%$ de respostas insatisfatórias, onde os discentes não tinham curiosidade em conhecer o ecossistema manguezal. O critério parcialmente satisfatório não foi computado. Após a ação educativa, houve um declínio no percentual das respostas satisfatórias diminuído para $76 \%$, já nas respostas insatisfatórias subiu para $24 \%$.

Após a ação educativa, usando o mesmo questionário anteriormente aplicado, demonstrou através dos indicadores de avaliação, sobretudo das respostas "Satisfatórias" e "Parcialmente Satisfatórias", que a maioria dos conceitos transmitidos foram bem absorvidos pelos alunos. Pereira; Farrapeira; Pinto (2006, p. 9), também percebeu que após a ação educativa, quase a metade da comunidade urbana do Recife apresentou uma avaliação satisfatória individual da aprendizagem sobre a importância dos manguezais, suplantando os jovens de outros municípios investigados nestes indicadores. 
O fato de a utilização da cartilha não ter sido um método eficaz, nas séries finais do ensino fundamental, pode estar relacionado ao fato de que os alunos nessa faixa etária, não se sentiram sensibilizados com esse tipo de atividade, podendo uma aula prática ser mais efetiva (SILVA; MAIA, 2020, p. 98). Esse fato constata a ideia empregada no estudo de Krasilchik (2004), na qual, ela relata que aulas práticas de caráter expositivo, são mais eficientes, pois não apenas se ouve falar, mas também se vive diretamente a realidade, o que sugere a aplicação de aulas de campo nos cursos.

Perante esses resultados, houve uma desmistificação de conceitos equivocados e impressões errôneas que os alunos entrevistados tinham acerca desse ambiente, comprovando a observação de Silva e Rodrigues (2013), onde ele expõe que é inevitável entender a concepção de uma população sobre meio ambiente antes de efetuar qualquer ação de Educação Ambiental acerca dos manguezais.

A utilização de um questionário mostrou-se eficaz tendo em vista que permite uma pesquisa espontânea, que verifica quais os conhecimentos de forma natural, sem induzir ou limitar respostas. Tal método foi utilizado também com êxito por Pereira, Farrapeira e Pinto (2006), que realizou sua pesquisa também sobre o ecossistema manguezal.

A ação educacional interativa demonstrou eficácia sobre o ecossistema manguezal, valendo-se do método de aproveitar o conhecimento cotidiano dos alunos e de sua comunidade para incentivar os alunos a conhecerem o lado científico do tema, facilitando assim, o processo de ensino-aprendizagem, tendo sido constatada a satisfação dos alunos em terem participado ativamente na reconstrução do seu próprio saber.

Os resultados satisfatórios obtidos ao final deste trabalho devem encorajá-los a uma contínua busca de novos caminhos para levar aos educandos assuntos abordados em livros didáticos de uma maneira mais prazerosa, compreensiva e contextualizada, usando exemplos locais.

\section{Conclusões}

Durante este estudo, nos dois níveis do ensino básico, as escolas analisadas mostraram que os docentes têm um conhecimento insatisfatório a respeito do tema manguezal, fato esse que resulta na ausência de suas abordagens em sala de aula;

O fato de os alunos morarem nas proximidades dos manguezais faz com que os mesmos conheçam a problemática da degradação do manguezal na comunidade. Apesar de não haver um projeto educativo na escola ou ação pública que enfatize esse contexto;

O desenvolvimento de intervenções didáticas proporcionadas pela aplicação da cartilha e do jogo de quebra-cabeça "Educa Mangue" foram essenciais para os resultados satisfatórios obtidos no ensino infantil e nas séries iniciais do ensino fundamental, uma vez que houve a promoção da construção 
dos conceitos ecológicos sobre o ecossistema manguezal e seus componentes biológicos, bem como os impactos antrópicos causados nesse ecossistema. Tais fatos contribuíram para a formação de um conhecimento crítico dos educandos, levando-os a refletirem sobre suas ações com relação ao meio em que residem.

Nas séries finais do ensino fundamental, após a intervenção através da cartilha, "Educa Mangue", não foram obtidos resultados satisfatórios, pois os discentes não se sentiram sensibilizados com esse tipo de atividade. Portanto, sugere-se que, para uma maior efetividade do conhecimento do ecossistema manguezal, a qual "prenda" a atenção e instigue a curiosidade dessa faixa etária dos alunos, a realização de uma aula de campo, já que assim os alunos não apenas ouviriam falar sobre, mas, sim, viveriam a realidade desse ambiente.

Conclui-se que a falta de ações de Educação Ambiental, bem como a ausência de materiais didáticos para discentes e docentes, e a falta de conhecimento por parte dos professores sobre a temática nas escolas pesquisadas, proporcionou resultados insatisfatórios no decorrer da análise.

Sugere-se a formação continuada dos educadores, a adoção de materiais didáticos específicos e a promoção da interdisciplinaridade e a transversalidade dos conteúdos relacionados ao manguezal a fim de efetivar a Educação Ambiental sobre a temática no ensino fundamental, especialmente, em escolas implantadas em regiões costeiras.

\section{Agradecimentos}

Ao -Instituto Federal de Educação, Ciências e Tecnologia do Ceará, IFCE - Campus Acaraú e o Laboratório de Ecologia de Manguezais (ECOMANGUE) por tornar possível a realização do estudo. As instituições de ensino básico e todos os professores e alunos que participaram do estudo.

\section{Referências}

ALBUQUERQUE, A.; FREITAS, E.; MOURA-FÉ, M. M.; BARBOSA, W. A proteção dos Ecossistemas de Manguezal pela Legislação Ambiental Brasileira. Geographia. v. 17 n.33. p. 126-153, 2015.

ALBUQUERQUE, R. M. V. L; FARIAS, E. M. N; MAIA, R. C. Educação Ambiental para o Ecossistema Manguezal: O papel dos pescadores artesanais. Conexões Ciência e Tecnologia. Fortaleza-CE, v.9, n.3, p.41-50, 2015.

ALMEIDA V. C.; COELHO, J. C.; FEITOSA, F.; PASTOR, D.;MONTE, G. caracterização estrutural do manguezal do rio tabatinga, suape, pe, brasil. tropical oceanography, recife, v. 42, n. 1 p. 33-47, 2014.

ARAÚJO, M.V.; SÁ FREIRE G. S.; COSTA, S. S. L.; PORTELA, J. P. Análise geoambiental da área estuarina do rio Acaraú, município de Acaraú - Ceará - Brasil, usando técnicas de sensoriamento remoto. In: Anais. XIV Simpósio Brasileiro de Sensoriamento Remoto, Natal, Brasil. p. 4561-4568. 2009. Disponível em: $<$ https://bit.ly/martesidinpe $>$. Acesso em: 5 mar.2019. 
BARBOSA, T.S.; FURRIER, M. Ocupações irregulares e impactos sócio-ambientais às margens do rio Sanhauá, Paraíba/Brasil. Revista Percurso - NEMO, Maringá, v.5, n. 2, p 91 - 107, 2013.

CARDOSO, R. B.; CARDOSO, T. A. L.; CAMAROTTI, M, F. Educação Ambiental nos anos Iniciais do Ensino Fundamental: Abordagem e percepção do ecossistema Manguezal. Revista Eletrônica do Mestrado em Educação Ambiental, v. 29, n.1, p. 1-13, 2012.

CORREIA, M. G. S. Aspectos históricos e impactos ambientais identificados no manguezal 13 de julho, aracaju/se. Anais do XI Congresso Brasileiro de Defesa do Meio Ambiente. 393p. 2015. Disponível em: <https://bit.ly/arquivo1438710974pdf>. Acesso em: 4 jan. 2020.

FARIAS, K. L; DE ANDRADE, R. C. B. Educação Ambiental: O manguezal no Ensino Fundamental. Revista Eletrônica do Mestrado de Educação Ambiental, v.25, n.1, 2010.

FARRAPEIRA, C.M.R.; SILVA, K.M.E.; LIMA, A.O. Percepção e concepção do manguezal vinculados ao ensino da Biologia em uma escola de Recife- PE. Educação Ambiental em Ação, Novo Hamburgo, v. 1, n. 19, p. 1-9. 2007.

FREITAS, D. L. R.; COSTA, A. C. P.; MIRANDA, F. F.; MELO, A. A.; SILVA, J. T.; BARBOSA, J. S. O manguezal, o professor e a sala de aula - Desenvolvimento de oficina sobre o ecossistema manguezal para professores da rede municipal de ensino de Macau-RN. Anais VII Congresso Norte Nordeste de Pesquisa e Inovação. Palmas, p.1-8, 2012. Disponível em: <https://bit.ly/propiftoedu>. Acesso em: 26 jun. 2020.

GARRIDO, L. S.; MEIRELLES, R. M. S. Percepção sobre meio ambiente por alunos das séries iniciais do Ensino Fundamental: considerações à luz de Max e de Paulo Freire. Ciência e Educação, Bauru, v. 20, n. 3, p. 671-685, 2014.

JACOBI, P. Educação Ambiental, cidadania e sustentabilidade. Cadernos de Pesquisa, v.33, n.118, p. 189-205, mar. 2003.

KRASILCHIK, M. Prática de Ensino de Biologia. 4.ed. São Paulo: EDUSP, 258p, 2004. MAIA, R.C. Manguezais do Ceará. Recife: Imprima, 2016, 55p.

MANSON, F. J.; LONERAGAN, N. R.; SKILLETER, G.A.; PHINN, S. R. An evaluation of the evidence for linkgens between mangroves and fisheries: a synthesis of the literature and identification os research directions. Oceanography and Marine Biology, v.43, p. $485-5152005$.

MEDEIROS, S. R. M.; CARVALHO, R. G.; PIMENTA. M. R. C. A proteção do ecossistema manguezal a luz da lei: 12.651/2012: novos desafios para a sustentabilidade dos manguezais do rio grande do norte. GEOTemas, Pau dos Ferros,Rio Grande do Norte, Brasil, v .4, n. 2, p. 59-78, 2014.

MELO, A. V. O. M; FARRAPEIRA, C. M. R; PINTO, S. L. Estratégias de Educação Ambiental sobre o manguezal junto a uma comunidade estudantil de Olinda-PE. Revista Eletrônica do Mestrado de Educação Ambiental, v. 21, n.1, p. 356-376, 2008.

OLIVEIRA, A. N.; DOMINGOS, F. O.; COLASANTE, T. Reflexões sobre as práticas de Educação Ambiental em espaços de educação formal, não-formal e informal. Revista Brasileira de Educação Ambiental. São Paulo, V. 15, N. 7, p. 09-19, 2020.

OLIVEIRA, R. R. S.; CARDOSO, I. S.; CRUZ, M. V. Educação Ambiental e análise dos ecossistemas de manguezais com alunos da educação básica. Geog Ens Pesq, Santa Maria, v. 23 n. 25 , p. 1-45, 2019.

Revbea, São Paulo, V.16, № 5: 115-133, 2021. 
PEDROSO, C. V. Jogos didáticos no ensino de Biologia: uma proposta metodológica baseada em módulo didático. Anais do IX Congresso Nacional de Educação EDUCERE. III Encontro Sul Brasileiro de Psicopedagogia. p. 3182-3190, 2009. Disponível em: <https://educere.bruc.com.br/arquivo/pdf2009/2944 1408.pdf>. Acesso em: 24 jul.2016.

PEREIRA, E.M.; FARRAPEIRA, C.M.R.; PINTO, S.L. Percepção e Educação Ambiental sobre manguezais em escolas públicas da Região Metropolitana do Recife. Revista Eletrônica do Mestrado em Educação Ambiental, Porto Alegre, v. 17, n.1, p. 244-261, 2006.

PINHEIRO, M.A.A.; SANTOS, C.M.H.; WUNDERLICH, A.C.; MILÃO-SILVA, F.; PERESCOSTA W.C. Educação Ambiental sobre manguezais na Baixada Santista: uma experiência da UNESP/CLP. Revista Ciência em Extensão, v.6, n.1, p.19-27, 2010.

RODRIGUES, G. S. DE S. C. COLESANTI, M. T. M. Educação Ambiental e as tecnologias de informação e comunicação. Sociedade \& Natureza, Uberlândia, v.20, n. 1, p. 51-66, 2008.

RODRIGUES, L.L.; FARRAPEIRA, C.M.R. Percepção e Educação Ambiental sobre o ecossistema manguezal incrementando as disciplinas de Ciências e Biologia em escola pública do Recife-PE. Investigações em Ensino de Ciências, v.13, n.1, p.79-93, 2008.

SILVA, R. J. R.; MAIA, R. C. Efetividade de ações práticas de Educação Ambiental para o ecossistema manguezal no ensino fundamental. Conex. Ci. e Tecnol. Fortaleza/CE, v. 14, n. 4, p. 95 - 106, ago. 2020.

SILVA, C. R. M.; RODRIGES, V. H. G. O QUE É EDUCAÇÃO AMBIENTAL. Para cinco catadores de papelão, no centro da Cidade do Rio Grande,RS. Seminário internacional de educação no mercosul. Anais XII seminário institucional. p. 1-17, 2013. Disponível em: <https://bit.ly/homeunicruz>. Acesso em: 22 jun. 2020.

SILVA, J, M; FRAZÃO, J. O; D' OLIVEIR, R.G;. Ecossistema Manguezal: vivências de Educação Ambiental em escolas no município de Natal, Rio Grande do Norte. Revista Eletrônica do Mestrado de Educação Ambiental, v. 24, n.1, p. 186-203, 2010.

SILVA, K. M.E.; AMARAL, E.M.R.; OLIVEIRA, M.A.B. Maré, mangue ou manguezal: uma análise de concepções de estudantes no Ensino Fundamental. Revista Brasileira de Pesquisa em Educação em Ciências, v. 12, n. 3, 2012.

SILVEIRA, L. S. DA; ALVES, J. V. O uso da fotografia na Educação Ambiental: tecendo considerações. Pesquisa em Educação Ambiental, v.3, n.2, p. 125-146. 2008.

SOUTO, F. J. B.; MARTINS, V. S. Conhecimentos etnoecológicos na mariscagem de moluscos bivalves no Manguezal do Distrito de Acupe, Santo Amaro - BA. Biotemas, v. 22, n.4, p. $207-218,2009$.

SCHAEFFER-NOVELLI, Y. A diversidade do ecossistema manguezal. In: Instituto Chico Mendes de Conservação da Biodiversidade. Atlas dos Manguezais do Brasil. Brasília: Instituto Chico Mendes de Conservação da Biodiversidade, 2018. p.21-34.

TEIXEIRA, E. D. S.; GOMES, P. N.; CARVALHO, C. S.; SILVA, M. M.; ARAGÃO, M. C. O. Utilização de filmes como material didático para ensino e aprendizagem da Educação Ambiental: estudo de caso. Revista Brasileira de Educação Ambiental. São Paulo, V. 14, N. 4, p. 87-105, 2019.

TOMLINSON, P. B. The botany of mangroves. Second Edition. Cambridge: Cambridge University Press, 2016. 418 p.

Revbea, São Paulo, V.16, № 5: 115-133, 2021.

revista brasileira

educação ambiental 